\title{
A Preliminary Idea on the Application of Art Therapy in Chinese College Students' Mental Health Education
}

\author{
Ya'nan Zheng \\ Department of Psychology \\ Gannan Medical University \\ Rural Medical Education Research Center \\ Gannan Medical University \\ Ganzhou, Jiangxi, China 341000
}

\author{
Yihui Li \\ Department of Psychology \\ Gannan Medical University \\ Ganzhou, Jiangxi, China 341000
}

\begin{abstract}
Art theory is using art as a medium for psychological treatment. This paper mainly introduces the art therapy in mental health education in Chinese colleges and universities, and preliminarily carries out the basic scheme of the art therapy, with a view to providing the reference for the development of future Chinese college the reform of mental health education and art therapy.
\end{abstract}

Keywords-art therapy; colleges and universities; mental health education

\section{INTRODUCTION}

Art therapy is a combination of art and psychological counseling and treatment, and rehabilitation training as a medical assistant method or the way of psychological intervention, through consultation in the art in the process of psychological, physiological changes and the expression of inner feelings to vent, apperceive, relieve stress, improve symptoms, adjust the cognition and mental, and to restore the mental health. ${ }^{[1]}$ Common treatment options are music therapy, literature, painting, sculpture, dance and so on. It has been widely used in clinical psychology and mental health education because of the way of treatment is random and easy to participate and not affected by the degree of cultural counseling, cognitive characteristics, characteristics of personality. At present, with the expansion of the college enrollment and increase of employment pressure, Chinese college students mental health has been the concern of the community. ${ }^{[2]}$ Student mental health education and the building of psychological counseling room has been extensively studied. But research shows that the utilization rate of college student's professional psychological counseling agencies is not high, the main reason is China's long-term lack to propagate the knowledge of psychological health and longterm discrimination of various mental disorders, which lead to colleges to worry about the negative evaluation of others if join psychological counseling agencies, to form a "stigma" [3] Thus, in China, although all levels of government institutions and schools have attached great importance to the mental health education of college students and increased incidence

Fund Project: Humanities training program of Gannan Medical University (RP201504) rate of all kinds of psychological problems by year, very few students initiatively turn to college psychological counseling center. Meanwhile, because of the combination of classroom education and daily propaganda using in college mental health education and lack of vivid content, there is little attraction to college students, causing the embarrassing situation of "hot and cold". While art therapy with vividness and interest is more attractive to colleges than theory teaching and there is no obvious "stigma" because of the form of art. Therefore, art therapy has a broad prospect and high utility value in the college students' psychological health. This paper according to current research status proposed preliminary ideas and solutions of art therapy in China, with a view to providing the reference for future college mental health education reform.

\section{The SignifiCANCE OF ART THERAPY IN COLLEGE MENTAL HEALTH EDUCATION}

\section{A. Increase the College Students' Attention to Mental Health}

Relative to teaching in large class, Psychological Health Education for College Students, it is easier to attract college students by music, painting, reading, writing, and other artistic ways to carry out the psychological health education. At the first semester of the mental health education after students in part related courses setting up art therapy can transform mental health, psychological adjustment and psychological intervention into article forms easily accepted, which is conducive to students enrolled to pay attention to the factors affecting mental health such as interpersonal communication, dormitory relationship, study pressure, and improve the level of mental health.

\section{B. Reduce the College Students' Contradiction to Mental Health}

Under China's long-term influence of social culture, accepting psychological counseling is equated with psychiatric treatment in the eyes of social customs, resulting in those who need psychological counseling resort to help for fear of negative evaluation of roommates and other students. Comparatively speaking, art therapy is easier to establish a 
good relationship between counseling and treatment because its characteristics are more likely to be accepted by college students and its rejection is lower. Organizing music therapy association, sitcom treatment groups and other ways make it easier for college students with mental problems and psychological perplexity to receive psychological counseling. This is very beneficial for mental health education in colleges.

\section{Help Enrich Campus Activities}

With the characteristics of music therapy, painting therapy, drama therapy and other art therapy methods, it is beneficial to enrich campus activities and improve the quality of colleges and universities by organizing psychological heath activities such as painting match, campaign, music appreciation of mental health.

\section{Open up a New Approach to Colleges' Mental Health Education}

Currently, the way of mental health education is relatively single in China's colleges and universities, mainly focused on the general psychological counseling, crisis intervention, campus propaganda of mental health knowledge, mental health education and so on, through art therapy which is a combination of art and mental health education can provide a new way for the university psychological health education, and can provide additional help for students seeking psychological help.

\section{A PRELIMINARY IDEA OF CONSTRUCTING THE ART THERAPY SYSTEM IN COLLEGES AND UNIVERSITIES}

\section{A. Establish College Art Therapy Studio}

At present, China's colleges and universities basically completed the construction of psychological counseling centers. On the basis of the hardware, using studio, music room, piano room, reading room and theater already equipped in most colleges and universities can jointly set up art therapy centers. According to music therapy, painting therapy, literary therapy in different ways carry out relative decoration and deploy corresponding therapeutic tool, such as audio-visual equipment, literature books, painting equipment, sand, works of art appreciation, HTP evaluation software. According to different visitors of gender, major, personality characteristics and psychological problems choose art therapy programs. Generally speaking, with existing equipments, setting up art therapeutic room of colleges and universities does not require additional input.

\section{B. Construct Art Therapy Team}

Software of teacher level is more important than hardware of art therapeutic room. Recently, all colleges and universities in China are equipped with mental health education and counseling teachers with basic ability of psychological assessment, psychological diagnosis and intervention, but relative to the psychology of professional knowledge, teachers of mental health are in the lack of knowledge of art. The backgrounds of Chinese professional counselors are mainly psychology, education, medicine, while counselors of music, painting, and literature are few. Therefore, each psychological consultation of colleges and universities should select teachers of mental health targeted, according to interest of each carry out appropriate art treatment. Meanwhile art therapy can also improve the mental health of humanistic quality and aesthetic taste, and build up better counseling relationship to achieve the purpose of improving the effect of psychological counseling.

\section{Strengthen College Volunteer Peer Counseling}

Because of lacking of mental health teachers in Chinese colleges, general psychological problems, such as interpersonal relationships, academic pressure and love, are counseled by students who are studying psychology at school, or those community members who are interested in mental health. It is difficult to obtain psychological perplexity of college students' trust, because of shallow qualifications and low psychological counseling skills level of peer students. While art therapy operation is relatively simple and easy to operate, it is easier for college students to cope with peer counselors by music appreciation, painting or sitcom playing. Thus, it is more favorable for construction of mental health system by training peer counselors using art therapy. There are more similarities between peer counselors and students in difficulty, helping counselors better understand problems than mental health teachers, and art therapy can make peer counseling staff better get the trust of the students help. In future, colleges can recruit students with artistic skills at school, regularly train the basic knowledge of psychology and art therapy, carry out class activities combining art therapy, hold the post of secretary of mental health teacher, independently counsel students with mental problems by art therapy, and propaganda campus activities using art therapy to achieve the purpose of mental health education.

\section{Introduce the Theory of Art Therapy into College Students' Psychological Health Education Class}

Introducing the theory of art therapy into college students' psychological health education class can play their interesting characteristics, and achieve the teaching purpose of attracting college students' attention to mental health. [5] During teaching, using the way of appreciating films, music, painting or selected readings to create a good phenomenon of discussing and stimulate their passion of learning, and organize team cooperation projects targeted such as drama, so that college students can support each other, explore and communicate to better understand teaching content.

\section{E. Popularize Related Campus Psychological Health Education Activities of Art Therapy}

At present, the activities of mental health education of Chinese colleges and universities are mainly workshops, psychological salon, lectures, solicit articles and training of expanding quality. While these entirely take artistic treatment as the carrier, integrating music appreciation, sand table appreciation of artistic elements into activities, permeating art therapy into psychological health education activities, stimulating students' passion and interest, and improving popularity of psychological health education by actively participating. 
All in all, facing low participation of Chinese colleges and universities of mental health education, the effective method is to integrate art therapy into mental health education. Although in the specific process, art therapy has certain requirements to mental health teachers in colleges and universities; it has incomparable advantages in popularization because its operation and characteristics are attractive to college students, which will inevitably play an important role in Chinese colleges and universities of mental health education.

\section{REFERENCES}

[1] Yan Hu, Chen Jindong, The Prospect of Application of Art Therapy in the Treatment of Children's Mental Problems, [J]Chinese Journal of Child Health Care, 2015,23 (5):491-493.

[2] Mai Xiaohan, Yang Jiewen, Analysis of Mental Health Status of Freshmen in a Medical College [J]. Chinese School Health, 2015,36 (7) : 1086-1088.

[3] Zheng Ya'nan, Hu Wen, Lai Yueyue, The Relationship of College Students' Professional Psychological Help Seeking Attitude, Psychological Stigma and Social Support, [J]. Chinese School Health, 2016,37 (1) : 78-80.

[4] Jiang Lihua, The Investigation and Analysis of the Current Situation of psychological Counseling Practitioners in Chifeng, [J], Journal of Chifeng University ( Natural Science Edition), 2014,30 (2) : 80-82.

[5] Ying Shuyue, A preliminary study on the modern value of art therapy in the perspective of College Students, [J] Journal of Taiyuan City Vocational College, 2015,5:79-81 